included a perception of being fine at work (49.5\%); followed by believing that work adjustments had already been made (7.5\%); and worry about involving the employer (4.7\%).

Patients agreeing to take part were more likely to be male (71.4\% vs. $56.2 \%)$, ever-smokers $(100 \%$ vs. $89.5 \%)$, slightly older (mean age 61.9 vs. 60.9) and have more severe airflow obstruction (19.5\% vs. $12.5 \%)$ than those declining.

One or more $\mathrm{OH}$ recommendations were identified for 14/16 $(87.5 \%)$ patients seen so far. These included: avoid substances/ materials at work (56.3\%); modify physical aspects of job (43.8\%); modify job tasks/work methods (37.5\%); modify work environment (18.8\%), change work organisation (31.3\%); use respiratory protective equipment $(6.3 \%)$.

Conclusions This is the first study to assess the feasibility of delivering an $\mathrm{OH}$ intervention to patients with COPD working in diverse occupations. Although uptake rates were low, modifiable factors in the work environment that could improve their symptoms and condition were identified for the majority who were assessed. The acceptability of recommendations and feasibility of involving the employer will be further explored.

\section{M148 INVESTIGATING THE FEASIBILITY OF AN ONLINE HEALTH RESOURCE WITH NURSE COACHING TO SUPPORT SELF-MANAGEMENT IN COPD}

1) Young, ${ }^{1} \mathrm{~F}$ Early, ${ }^{2} \mathrm{~S}$ Wisbauer, ${ }^{1} \mathrm{~K}$ Homan, ${ }^{1} \mathrm{~J}$ Fuld, ${ }^{1} \mathrm{~L}$ Tojo. ${ }^{1}$ Cambridge University Hospitals NHS Foundation Trust, Cambridge, UK; ${ }^{2}$ UK Preventive Medicine, Addlestone, UK

\subsection{6/thoraxjnl-2014-206260.443}

Introduction Pulmonary rehabilitation includes self-management support for COPD but is not suitable for or accessible to all. Web based approaches have potential to provide self-management support but effectiveness is not consistently demonstrated and issues of reach and adoption are relatively unstudied.

We performed a mixed methods before-and-after study of an intervention comprising web-based health promotion for LTC self-management, The Prevention Plan $^{\text {TM }}$ (TPP), with integrated nurse coach support. This report describes the qualitative evaluation. The aim was to understand the benefits gained and the characteristics of patients most likely to benefit.

\begin{tabular}{|c|c|}
\hline \multicolumn{2}{|l|}{ Benefits from the programme } \\
\hline Sub-themes & Description \\
\hline $\begin{array}{l}\text { Increased motivation for } \\
\text { self-management behaviours } \\
\text { Use of self-management }\end{array}$ & $\begin{array}{l}\text { Physical activity, healthy eating and quitting smoking. Raised awareness of healthy options and of current behaviours and habits, and introducing new behaviours, } \\
\text { e.g. replacing some foods in the diet. }\end{array}$ \\
\hline $\begin{array}{l}\text { skills } \\
\text { Increased access to }\end{array}$ & Use of goal setting and pacing techniques to aid in behaviour change. \\
\hline $\begin{array}{l}\text { information resources } \\
\text { Enhanced understanding }\end{array}$ & Links to other external sources of information, providing further information on a wide range of subjects related to healthy lifestyles and COPD. \\
\hline of lifestyle risk factors & How factors such as weight can impact on health. \\
\hline \multicolumn{2}{|c|}{ Facilitators to gaining benefits } \\
\hline Sub-themes & $\begin{array}{l}\text { Description } \\
\text { Patients were able to register and self-monitor their progress towards goals and gain support and supervision from the nurse coach. The greatest benefit from } \\
\text { action plans was gained where patients were motivated and committed towards a specific goal, such as losing weight or quitting smoking, but did not have a self- }\end{array}$ \\
\hline Use of action plans in TPP & $\begin{array}{l}\text { management strategy to implement the change. } \\
\text { Ongoing contact through email, phone or visits provided progress checking and support for action programmes and behaviour change. The email function within } \\
\text { TPP was used frequently by patients to support them in their use of TPP. The nurse coach was a driving force for patients' motivation and involvement in the action }\end{array}$ \\
\hline Nurse coach contact & programmes, improving their self-management skills and quitting tobacco. For some, this was more important than the TPP website. \\
\hline $\begin{array}{l}\text { Health Risk Assessment } \\
\text { Hand-held Personal Health }\end{array}$ & Completing the HRA was beneficial for patients who had not attended PR or who had little awareness of their lifestyle risk factors. \\
\hline Plan & Some patients found it more convenient and user-friendly to use the book rather than the website. \\
\hline Patient's own & \\
\hline determination & Self-motivation to make a change. \\
\hline \multicolumn{2}{|l|}{ Barriers to gaining benefits } \\
\hline Sub-themes & $\begin{array}{l}\text { Description } \\
\text { Despite the nurse coach support some self-motivation was required on the part of the patient to use the website, including the action plans. Some patients, particu- } \\
\text { larly those who had attended Pulmonary Rehabilitation in the past, preferred the more interactive approach in PR with the opportunity to observe others doing }\end{array}$ \\
\hline Lack of personal contact & $\begin{array}{l}\text { things, rather than having to rely to a great extent on their own self-motivation and the impersonal nature of a web programme. } \\
\text { Content was insufficiently tailored in terms of: overlap between information provided in TPP and that provided in other rehabilitation programmes which patients }\end{array}$ \\
\hline $\begin{array}{l}\text { Lack of tailoring of } \\
\text { information }\end{array}$ & $\begin{array}{l}\text { had attended; difficulty finding way to information that was personally relevant; poor fit between patients who regard themselves as having a high level of self- } \\
\text { management skill and the level of support provided by TPP. }\end{array}$ \\
\hline Lack of user-friendliness & $\begin{array}{l}\text { Navigation was difficult for some patients, especially through a large amount of information, making them opt for other alternatives or stop using the programme } \\
\text { out of frustration. }\end{array}$ \\
\hline Technical problems on & \\
\hline the website & Problems such as links being unavailable slowed patients' progress and caused frustration. \\
\hline Physical discomfort & Physical discomfort sitting at a computer and poor eyesight. \\
\hline
\end{tabular}


Method Nineteen patients were recruited in two waves from May 2012-January 2013. Key selection criteria included for group $1 \mathrm{FEV}_{1}<50 \%$ predicted and for group $2 \mathrm{FEV}_{1}<75 \%$ predicted.

Semi-structured interviews were scheduled for one month and three months after recruitment and were focused around experiences of the programme, benefits and self-management behaviours.

Qualitative data were imported into NVivo 10 and analysed through thematic content analysis. Two researchers discussed the themes and subthemes to ensure non-redundant categorization. Results Fifteen patients were interviewed. Key benefits: increased motivation for self-management, use of self-management skills, increased access to resources and enhanced understanding of lifestyle risk factors. Benefits were facilitated by use of action plans within TPP, nurse coach support to on-going motivation and completion of a health risk assessment by those with little awareness of lifestyle risks. Barriers to gaining benefit included preference for one-to-one contact, insufficient tailoring of website content and difficulties with website navigation. Patients most likely to benefit were those who: wanted to change but had no behavioural strategy; had little previous disease education; had an autonomous sense of self-determination.

Conclusions The programme provided good support for the action phase of behaviour change, but less so for the motivational phase. Patients who were ready to change but did not have knowledge, skills or strategies benefited the most. When implementing a behaviour change programme providers should identify whether it addresses motivation and/or behaviour and assess potential participants accordingly. People who are not ready or able to change may derive little benefit from a behavioural programme.

\section{IPF: education, information and health status}

\section{M263 A QUARTER OF IPF PATIENTS NOT ELIGIBLE FOR PIRFENIDONE TREATMENT DUE TO THE NICE CRITERIA SIGNIFICANTLY DECLINE OVER TIME}

N Chaudhuri, CT Leonard. University Hospital of South Manchester, Manchester, UK

\subsection{6/thoraxjnl-2014-206260.444}

Introduction Pirfenidone has NICE approval and is recommended for patients with IPF if the FVC is $50-80 \%$. We hypothesised that this would disadvantage a significant cohort of IPF patients who have moderate reduction in transfer factor despite preserved FVC.

Methods We present longitudinal data capturing 38 IPF patients who had FVC greater than $80 \%$ and not eligible for pirfenidone treatment.

Results Since NICE approval in July 2013, 43 patients were eligible for pirfenidone as per the NICE criteria and 38 (47\%) patients were outside the NICE criteria. Of those outside the NICE criteria, the average FVC was 98\% (81-145) and average DLCO was $58 \%(21-88)$. Sixteen (42\%) patients had a DLCO $<55 \%$, nine $(24 \%)$ had DLCO of $56-70 \%$ and nine (24\%) with DLCO above $70 \%$. Only nine (24\%) had CT evidence of emphysema. We had one or more serial lung function results for 17 (49\%) patients. A total of 9/38 (24\%) patients demonstrated an absolute decline in FVC of over $10 \%$ and one patient had an absolute DLCO decline of over 15\%. Only one of these patients became eligible for pirfenidone treatment.
This retrospective data demonstrates that the sole use of FVC in the NICE criteria for treating IPF disadvantages patients who demonstrate a significant reduction in transfer factor despite FVC greater than $80 \%$. In this study this reduced transfer factor and preserved FVC can only be attributed to the presence of coexisting emphysema in 9/38 (24\%) of patients. Ten (26\%) IPF patients not treated with pirfenidone because they did not meet the NICE criteria demonstrate a clinically significant decline in their lung function. Despite this the majority are still not eligible for treatment with pirfenidone.

We would therefore advocate following our European partner countries and using both FVC and DLCO as per the CAPACITY criteria when assessing patient suitability for pirfenidone treatment for IPF, as the use of FVC alone with an upper limit of $80 \%$ excludes a substantial cohort of IPF patients who have preserved FVC, moderately reduced DLCO with or without the presence of coexisting emphysema and over time a quarter of these patients demonstrate lung function decline.

\section{REFERENCES}

1 CAPACITY Study Group. Pirfenidone in patients with idiopathic pulmonary fibrosis (CAPACITY): two randomised trials. Lancet 2011;377:1760-69

2 http://www.nice.org.uk/nicemedia/live/14156/63713/63713.pdf

\section{M264 HEALTH AND ECONOMIC IMPACT OF PRESCRIBING PIRFENIDONE}

N Chaudhuri, CT Leonard. University Hospital of South Manchester, Manchester, UK

\subsection{6/thoraxjnl-2014-206260.445}

Introduction Pirfenidone is the only licensed drug in Europe for Idiopathic Pulmonary Fibrosis (IPF). Clinical trials (1) have demonstrated efficacy in reducing decline in forced vital capacity (FVC), improving progression free survival and reducing mortality. The translation of clinical trial results to clinical practice is a focus of interest.

Methods We describe our experiences in prescribing pirfenidone in a single centre observational study of 96 patients from September 2011 to April 2014.

Results This is an extension of our published work (2). Prior to NICE approval we recruited 49 patients in twenty months. NICE approval resulted in a $140 \%$ increase in pirfenidone prescribing. Patient demographics at baseline are shown in Table 1. $54(56 \%)$ patients continued treatment, 19 (20\%) discontinued treatments due to adverse effects (AEs), there were $17(17 \%)$ deaths and $4(4 \%)$ patients were transplanted. Patients that died had lower diffusing capacity (DLCO) at baseline compared to those that continued treatment $(32.9$ vs $47.7 \mathrm{p}<0.0001)$. Patients that discontinued treatment due to AEs did so within six months and had lower body mass index ( 25.1 vs $29 \mathrm{p}=0.002$ ) and DLCO (38.8 vs $47.7 \mathrm{p}=0.007)$.

There were a total of 206 AEs in 77 (79\%) patients. The majority were gastrointestinal in nature. Of these adverse effects the majority were self-limiting and resolved with simple measures. $44(21 \%)$ resulted in a dose reduction, $23(11 \%)$ resulted in a temporary discontinuation, in 101 (45\%) AEs treatment was unchanged and 38 (19\%) AEs resulted in drug discontinuation.

In selected patients we had one or more lung function results before (34\%) and after (50\%) pirfenidone treatment. Eighteen months prior to pirfenidone treatment there was an observed reduction in mean\% predicted FVC over time. Accepting limitations of missing data, this decline appeared to stabilise over twelve months after commencement of pirfenidone. 